different kinds of model. There are deterministic and stochastic models, descriptive and predictive models, dynamic models, compartment models, matrix models, multivariate models, optimisation models, game theory and catastrophe theory models, all illustrated with particular examples. For a brief flavour of these, I can think of no better text. My main criticisms are aimed at the ten tables with computer listings. These convey little useful information and the space could have been more profitably used.

The final book in this selection, Statistics, by D. Freedman, R. Pisani and R. Purves (W. W. Norton: New York; \$13.95, including an Instructor's Manual), is a general statistics text, and not aimed especially at biologists. It fits into this quartet only in that a good grounding in statistics is important for any ecologist. The book is intended for "nonstatisticians who want to learn some statistics in order to go about their affairs", and relies on the plentiful use of exercises and a smooth narrative. The authors' have made no

\section{Sociobiological literature reviewed}

THE three books reviewed here all reflect the recent growth in. sociobiology. They are, nevertheless, very different in character. Readings in Sociobiology and The Sociobiology Debate: Readings on Ethical and Scientific Issues are collections of reprinted papers (there also are some new articles in the latter volume), while Sex, Evolution and Behavior is a new textbook written at a level suitable for first- and second-year undergraduates.

The contrast between the two sets of readings is graphically demonstrated by the fact that only two out of 60 articles in the two are identical: Wynne-Edwards on group selection and Trivers on reciprocal altruism. Readings in Sociobiology (Freeman: San Francisco and London; hardback $\$ 18, £ 9.50$; paperback $\$ 9, £ 4.50$ ), edited by T. H. Clutton-Brock and P. H. Harvey, is aimed at undergraduate or graduate student audiences, and it covers the subject of sociobiology as understood by most academics working in the field. Concepts such as inclusive fitness, evolutionarily stable strategy, parental investment, and cost-benefit ratio crop up on every other page. The Sociobiology Debate (Harper and Row: New York and London; \$12.95, £7.95), edited by A. L. Caplan, is largely about the subject as concessions at all to what they call "pluginski", the rather mindless application of a statistical technique to a problem, and have whenever possible banished equations from the text. The result approaches 600 pages of text and notes with an almost complete absence of the different computational recipes needed in the application of everyday statistics. This over-reaction, together with the neglect of any treatment of the Poisson and negative binomial distributions that are so important in ecology, leaves a book ill-suited to the ecologically minded student.

For a concluding remark, I return to Hutchinson's An Introduction to Population Ecology. It stands apart from the rest as a work of distinction, that should be studied for its scientific content and savoured for its recondite footnotes.

M. P. Hassell

M. P. Hassell is Reader in Insect Ecology in the Department of Zoology and Applied Entomology at Imperial College, University' of London, UK.

sections are the core of the collection. There is probably some value in a number of book reviews, short comments, and the Wilson versus Science for the People exchanges collected together; however, the overall result has little coherence. Editorial summaries might have helped, but Caplan's own contributions are sometimes confusing in themselves. This is illustrated by an amusing juxtaposition at the start of the book. E. O. Wilson writes in his Preface "Sociobiology is a discipline, not a particular theory". Two pages later, Caplan starts his introduction by saying of sociobiology "The very boldness of the theory ....".

M. Daly and M. Wilson's clearly written book (Sex Evolution and Behavior; Duxbury Press; North Scituate, Massachusetts) does more to disperse the clouds of confusion, both deliberate and unintentional, about what sociobiologists have said, in particular the little they have said about human behaviour. After a brief introduction to modern ideas about natural selection, the book races through the cost of sex, sexual selection, parental investment, mating systems, life-history strategies, the physiology and ontogeny of sex differences and finally human sexual behaviour. The style of writing is direct and easy to follow; the contents accurate within the constraints of an elementary treatment. A wide range of literature including evolutionary ecology, anthropology, physiology, psychology and sociology is discussed.

Daly and Wilson are strong advocates of the view that sociobiology has a lot to say about human behaviour. Those who think that this is an overenthusiastic standpoint will at least find that Daly and Wilson summarise their ideas with clarity. I quote from their last chapter. In discussing a statement of the Science for the People Sociobiology Study Group they say "Consider the following excerpt from a statement recently signed by thirty-five authors, some of them wellknown scientists:

determinists assert that the possibility of change in social institutions is limited by biological constraints on individuals. But we know of no relevant constraints placed on social processes by human biology. There is no evidence from ethnography, archaeology or history that would enable us to circumscribe the limits of possible human social organisation."

What can this mean? If human gestation, infantile helplessness, language capacity, sensory systems, cognitive abilities, maturational rates, senescence, and so on, are not "relevant constraints placed on social processes by human biology" whatever could be?"

John R. Krebs and others; 1960s 'human ethology' (for example, Lorenz); philosophers comments; the biology of sociobiology (Hamilton, and others); and two long sections on the polemics arising out of E. O. Wilson's book. These last two
John R. Krebs is Lecturer in Zoology at the Edward Grey Institute of Field Ornithology, University of Oxford, UK. 